Fanum

Sociológico

\section{Forum Sociológico}

Série II

23 | 2013

Número 23

\title{
O lugar do consumo na problemática identitária contemporânea
}

\section{Cristina Santos}

\section{(2) OpenEdition}

1 Journals

\section{Edição electrónica}

URL: https://journals.openedition.org/sociologico/821

DOI: 10.4000/sociologico.821

ISSN: 2182-7427

\section{Editora}

CICS.NOVA - Centro Interdisciplinar de Ciências Sociais da Universidade Nova de Lisboa

\section{Edição impressa}

Data de publição: 1 novembro 2013

Paginação: 51-58

ISSN: 0872-8380

\section{Refêrencia eletrónica}

Cristina Santos, «O lugar do consumo na problemática identitária contemporânea», Forum Sociológico [Online], 23 | 2013, posto online no dia 01 janeiro 2014, consultado o 30 março 2022. URL: http:// journals.openedition.org/sociologico/821 ; DOI: https://doi.org/10.4000/sociologico.821

Este documento foi criado de forma automática no dia 30 março 2022.

(c) CICS.NOVA 


\title{
o lugar do consumo na problemática identitária contemporânea
}

\author{
Cristina Santos
}

\section{A identidade}

1 Somente na segunda metade do século XX a terminologia identitária é incluída no vocabulário das ciências sociais e a problemática referente à construção da identidade é objeto de tratamento sistematizado (Costa, 2008). Não obstante a atual tendência para encarar o campo social numa perspetiva identitária (Ransome, 2005) e a importância do acentuado crescimento de obras sociológicas que abordam a identidade, esta difusão é recente e ainda insuficiente, para além da apropriação indiferenciada de que o conceito é alvo (Costa, 2008).

2 A identidade é, em sociologia, um conceito multifacetado, pois permite diversas abordagens: identidade nacional; identidade geracional; identidade de género; identidade étnica; entre outras (Costa, 2008). Porém, destaca-se uma conceção dicotómica: a identidade pessoal, associada à noção de unicidade e singularidade (Goffman, 1982; Giddens, 1989, 2004), e a identidade social, ligada ao conceito de semelhança (Giddens, 2004). A identidade do «eu-nós» representa a resposta à dúvida que o sujeito tem em saber quem é, simultaneamente, enquanto ser individual e social (Ybema et al., 2009).

3 A construção de uma identidade é um jogo complexo que carateriza as sociedades atuais (Pinto, 1991): "Today we have a great deal of choice about who we want to be and the kind of life we want to lead" (Ahuvia, 2005: 172). De facto, trata-se de uma problemática que surgiu com a modernidade, ao propulsar os indivíduos para uma dinâmica social em que predominam a liberdade e as possibilidades de escolha para modificar a própria identidade, consoante a vontade demonstrada. Instaurou-se um apelo constante à novidade e à transitoriedade, confrontando os sujeitos com esse desafio e 
responsabilidade (Giddens, 1989). Com a flexibilidade identitária, a emancipação do indivíduo implica incertezas (Bauman, 2007). Numa sociedade apelidada de risco e caracterizada pela mudança, insegurança e obrigatoriedade de decidir (Franklin, 1998), a responsabilização das escolhas, as acções que acarreta e as respectivas consequências recaem sobre os actores sociais (Bauman, 2007). Segundo Cruz (2009), a passagem de um grande número de responsabilidades, que anteriormente se sociabilizavam, para os sujeitos prende-se com a chegada da sociedade de consumo.

4 Assim, uma das questões fulcrais que se impõe aos indivíduos é: "Quem devo ser?" (Giddens, 1989). O sujeito é confrontado com um número crescente de alternativas, dispondo de uma maior margem seletiva (Elias, 1993). Este panorama poderá reforçar a ideia da existência de uma contemporânea crise de identidade, já que os processos históricos que, aparentemente, sustentavam a fixação identitária começaram a entrar em colapso (Woodward, 2005):

"No passado, quando as identidades se reproduziam, as pessoas singulares não tinham nenhuma escolha: o grupo, em nome da tradição, submetia cada um à sua lei e o indivíduo não era mais do que um átomo de um corpo social que se perpetuava tal e qual. Mas, hoje em dia, as pessoas singulares aspiram, cada vez mais, a poder escolher a sua identidade (...)" (Wieviorka, 2007: 88).

Numa sociedade em rápida transformação, como a atual, a herança societal perde, de uma forma cada vez mais célere, a sua importância, definindo-se mais pelo futuro do que pelo respetivo passado (Touraine, 1982). Esta indeterminação identitária e consequente dilema encontravam-se ausentes das sociedades tradicionais, nas quais a identidade era socialmente atribuída e imposta, prevalecendo uma lógica condicionalista. Consequentemente, os conteúdos coletivos permaneciam idênticos, transitando nos contextos geracionais, pelo que a mudança de identidade esbarrava numa delimitação previamente estabelecida (Nunes, 1968). Porém, presentemente, impera a mobilidade (Ferreira, 2000), uma vez que nenhuma identidade é "dada" à nascença, sendo um projeto negociável e progressivo, executado ao longo da vida (Bauman, 2007).

6 Ainda assim, Gove e Watt (2004) assinalam que, apesar de o indivíduo se poder sentir inteiramente livre na construção da sua identidade, tal não acontece, uma vez que a escolha identitária é moldada pela sociedade, em que fatores sociais e culturais influenciam o processo. Também Woodward (2004) sublinha que a problemática identitária envolve alguma possibilidade de o sujeito optar, ainda que com limitações. Há algum controlo do ator social na própria construção identitária, mas poderão existir tolhimentos externos que o limitarão. Existe uma tensão entre o domínio exercido pela pessoa na edificação da sua identidade e o que é incutido sobre a própria pelos restantes indivíduos.

7 Como consequência, tal como referem Ybema et al., a construção identitária envolve um sistema negocial entre o "eu" e os "outros", daí a identidade ser, simultaneamente, o que é projetado e percecionado: “(...) which produces a socially negotiated temporary outcome of the dynamic interplay between internal strivings and external prescriptions, between self-presentation and labeling by others, between achievement and ascription and between regulation and resistance" (Ybema et al., 2009: 101). A criação identitária aparenta articular a relação entre o sujeito e a sociedade, pelo que encontra as suas origens no debate sobre agência e estrutura (Ybema et al., 2009). 
8 A dimensão identitária sempre fora um problema (Bauman, 1995, 2000, 2007; Vieira, 1999) transversal a qualquer sociedade (Vieira, 1999). Assim, se na modernidade a questão se centrava na forma de construir uma identidade e a manter estável, no que Bauman $(1995,2000,2007)$ denomina como a "modernidade sólida", numa "tirania da eternidade", com o pós-modernismo surge a necessidade de evitar a respetiva fixação e conservar todas as opções em aberto, no que o autor apelida de "modernidade líquida", caraterizada por uma "tirania do momento". No primeiro caso, a palavra-chave é "criação", em que as identidades eram construídas em "ferro e betão", no segundo estas são dispostas em "plástico biodegradável", sendo o conceito implícito: "reciclagem".

9 Efetivamente, com o desenvolvimento do pós-modernismo chega o reconhecimento de que o indivíduo não tem apenas uma identidade, dada a respetiva natureza incerta, fragmentada (Hall, 2005), complexa (Miller et al., 1998), multíplice (Ransome, 2005) e impura (Pinto, 1991). Sendo a identidade composta por várias dimensões, assentes em múltiplas pertenças (Maalouf, 2002), estas serão, por um lado, laços que unem os indivíduos aos seus semelhantes e, simultaneamente, representam a especificidade individual. Pais (2002) afirma ter experimentado uma "colonização do eu", adquirindo múltiplas e díspares possibilidades de "ser". Como se processa este mecanismo? Através da incorporação da informação do meio que rodeia o indivíduo, exposto às dinâmicas circulantes do quotidiano, pelo que as variadas pertenças sociais são constitutivas de identidades ambivalentes. A este propósito, Cruz (2009) afirma que o ator social é plural, em função da diversidade de contextos em que é socializado.

Goffman (1982) defende que a construção identitária, enquanto um contínuo processo social, permite o abandono de uma identidade e a procura de uma nova, pelo que os sujeitos acumulam uma multiplicidade de "apresentações do eu". Também Mead (1967) realça o facto de qualquer pessoa dividir-se em vários “eus". Para Lewis e Phoenix (2004), todo o indivíduo acumula um conjunto de diferentes identidades, simultaneamente, mediante as diferentes posições sociais ocupadas. Ainda assim, Maalouf (2002) acredita que, ao reivindicar uma identidade mais complexa, o indivíduo é marginalizado, dada a dificuldade em compreender uma identidade compósita.

11 Rattansi e Phoenix (2001) acreditam que esta conceptualização identitária potencia o eventual surgimento de contradições ou inconsistências nas práticas dos sujeitos. Também Woodward $(2004,2005)$ refere que as diferentes identidades assumidas pelo indivíduo, exigência da complexa vida moderna, poderão entrar em tensão entre si. Tal como Silva (2005), que defende a existência de identidades fragmentadas, inconsistentes e opostas, Kopytoff (1986) e Tarlo (1996) mencionam que estas poderão ser múltiplas e conflituosas.

12 Já Velho (1994), por sua vez, frisa que o facto de a identidade dos indivíduos se encontrar

em permanente reconstrução não inviabiliza tratar-se de uma transição pacífica. A este propó-

sito, Schwartz (1999) salienta que, apesar de a acumulação identitária poder ter algum impacto sinuoso, existindo diversos "eus" em paralelo, deverão ser suficientemente coerentes para evitarem uma crise de identidade. Giddens (2004) afirma que a pluralidade identitária não potencia o surgimento de conflitos, pois a maioria dos sujeitos organiza o sentido e a experiência das suas vivências em torno de uma identidade principal, relativamente contínua no espaço e no tempo. Elias (1993) defende, de igual forma, que há uma continuidade evolutiva, tal como Vieira (1999), que 
realça a existência de uma relativa homogeneidade identitária. Também Maalouf (2002) acredita que a identidade não se compartimenta, sendo una e vivida no seu todo e não como um aglomerado de pertenças autónomas e justapostas. Por outro lado, Quadrado (2006) inferira que, independentemente de a identidade do indivíduo ser constantemente deslocada, o ator social perceciona-se como sendo o mesmo sujeito.

13 A pluralidade encontra-se no cerne da questão identitária, dada a hibridez que a carateriza (Rattansi e Phoenix, 2001; Wieviorka, 2007): “(...) we rarely think of ourselves as one thing at all times and in all places" (Miller et al., 1998: 23). É por esse motivo que, quando se aborda a problemática identitária, é instantânea a sua ligação a uma falsa imagem de harmonia, de lógica e de coerência, algo que com o fluxo das experiências vividas pelos indivíduos aparenta faltar, pelo que só ilusoriamente as identidades são fixas e permanentes (Bauman, 2000). Ainda que haja uma tendência para a fixação identitária, esta é, simultaneamente, uma impossibilidade (Silva, 2005). Ao aparentar estabilidade, uma identidade estará a passar por uma etapa momentânea e transitória, por um estádio de resiliente engano (Ybema et al., 2009).

14 A este repertório de papéis sociais associam-se as noções de metamorfose (Velho, 1994) e nomadismo (Lehmann et al., 1998). Efetivamente, as identidades nunca estão total e definitivamente estabelecidas, não detendo um caráter estanque (Otto e Otto, 1971), ao encontrarem-se num relativo estado de formação e mutação, ao serem provisórias, inacabadas (Rattansi e Phoenix, 2001; Hall, 2005; Silva, 2005), mutantes (Elias, 1993) e dinâmicas (Miller et al., 1998). o processo social implicado na formação identitária é, inequivocamente, recursivo, reflexivo e multifacetado, por se encontrar em constante construção (Ybema et al., 2009), pelo que só cessa com o falecimento do ator social (Otto e Otto, 1971). Se esta dinâmica é frequentemente referida como a "procura identitária", a qual é justificada pelo facto de os seres humanos necessitarem de uma teoria central "sobre quem são" antes de poderem começar a elaborar o seu "eu" (Schwartz, 1999), Otto e Otto afirmam ser mais correto designá-la como "(...) «the ongoing development of identity»" (Otto e Otto, 1971: 405).

É por esse motivo que a definição identitária é um processo que envolve alguma complexidade, já que não se trata de um mecanismo uniforme, nem estático, mas flexível e em permanente redefinição, cuja abordagem deverá incluir a análise dos diversos aspetos sociais e culturais que rodeiam o indivíduo (Gonçalves, 1994). Nenhum elemento que compõe a vida societal pode ser plenamente compreendido sem relevar a respetiva cultura particular na qual ocorre (Goffman, 1983): "Aquilo que é critério de distinção identitária importante numa dada sociedade ou situação social pode não ter qualquer significado noutro local ou noutra época (...). Tudo depende da relevância identitária que é dada a esta ou àquela caraterística, no decurso dos processos sociais" (Costa, 1992: 53).

É axiomático que a construção identitária se sedimenta na distinção: para se saber quem se é, torna-se necessário estabelecer-se quem não se é (Featherstone, 1994; Silva, 2005; Ybema et al., 2009). Aliás, a marcação da diferença, a partir da qual as identidades são fabricadas, é o componente-chave em qualquer sistema classificativo (Woodward, 2005). As identidades só podem ser "lidas" a contrapelo, ou seja, não através da estabilidade, mas como algo que é construído de forma desigual (Hall, 2005). Assim, o conceito identitário apresenta uma índole comparativa, dado que a definição dos indivíduos só é efetivada relativamente à demarcação dos outros sujeitos (Costa, 1992): 
não existe nenhuma identidade do "eu" sem a identidade do "nós" (Elias, 1993), dado o seu caráter relacional (Lewis e Phoenix, 2004).

A similitude/uniformidade e a diferenciação/singularidade são dimensões centrais na construção identitária, sendo com base numa dialética de identificação entre a interação interna e externa que estas se constituem (Ybema et al., 2009). Ransome frisa esta ambivalência, salientando o papel do consumo no alentar desta dinâmica: "People still wanted to see themselves as part of society and take advantage of the support and protection this provides, but without becoming entirely assimilated into it. (...) one of the dilemmas which lies at the heart of the identity/consumption relationship which is that through consumption we are expressing a need to align ourselves with others, and yet we also consume in order to distinguish ourselves from them" (Ransome, 2005: 106).

\section{0 consumo}

18 Apesar de o consumo ser irremovível da condição humana (Bauman, 2007) e de ter invadido a vida dos indivíduos (Baudrillard, 1995), só em 1980 a temática ganha maior expressividade na sociologia. Até então, aparentava ser um conceito do domínio exclusivo de economistas, publicitários e marketers (Bocock, 1993), tendo sido encarado como uma mera função do processo económico e não como um autónomo fenómeno social (Friedman, 1999). Portanto, é somente no final do século XX que a maioria dos sociólogos reconhece a centralidade que o consumo assume na atual problemática identitária (Rattansi e Phoenix, 2001), através da respetiva capacidade de providenciar uma área flexível para a construção das maleáveis identidades contemporâneas (Miles, 2000). Segundo Queiroz (2005), o significado cultural do consumo na construção identitária é de tal ordem que se pode considerar que nele reside a mais forte motivação da ação coletiva nas sociedades desenvolvidas nos finais do século passado.

Uma esfera que oferecia estabilidade identitária e um sentimento de pertença ao indivíduo entrou em declínio: “(...) «a job for life» (...)” (Woodward, 2004: 29). Com a deslocação da ênfase da produção de bens para o seu consumo (Duarte, 2009), assiste-se à passagem da sociedade dos produtores para a dos consumidores. Trata-se de um processo gradual de emancipação dos sujeitos, que deixaram de não ter escolhas, passando de um cenário de constrangimentos e de falta de liberdade para um panorama em que prevalece a autonomia individual (Bauman, 2007). Com esta transição, afirma Bauman, a sociedade, repleta de múltiplas e variadas oportunidades, dá primazia aos seus membros enquanto consumidores, uma vez que a vida organizada em torno do papel de produtor tende a ser normativamente regulada, ao invés do consumo, onde não existem regras (Bauman, 2000), pelo que o indivíduo é alvo de menos restrições (Warde, 1994).

Porém, Doherty (2009) critica Bauman, por não concordar com o autor quando este argumenta que o trabalho desempenha um papel diminuído na sociedade contemporânea, ao ter perdido a posição privilegiada de outrora na construção identitária. Os resultados da pesquisa que Doherty desenvolvera demonstram que a esfera laboral mantém a sua importância. De facto, Mackintosh e Mooney (2004) realçam que quando um indivíduo estabelece um contacto relacional com alguém, pela primeira vez, pergunta qual a respetiva profissão, numa tentativa de o conhecer, dado o relacionamento efetivado entre o emprego detido e a identidade. No entanto, os autores, tal como Ransome (2005), acreditam que a ocupação profissional desempenha 
um papel menor na atual problemática identitária. Crane (2000) realça a crescente relevância atribuída ao consumo, em detrimento da esfera laboral, dado o respetivo contributo para a construção da identidade.

21 É através do consumo que grande parte dos sujeitos procura expressar a liberdade, o poder e as suas aspirações sociais (Tomlinson, 1990), dada a autonomia e a independência que o caraterizam (Ransome, 2005). O consumo moderno é individualista, uma vez que o ator social detém possibilidade de escolha. Se outrora se assistia à autoridade que a tradição impunha, presentemente é o indivíduo quem dita as regras (Campbell, 2004). Para Warde (1994), a capacidade para escolher reside no centro do debate sociológico sobre práticas consumistas. $\mathrm{O}$ autor realça que, quando o consumidor toma as suas opções de consumo, sabe que há poucas sanções.

Contudo, e por outro lado, Warde (1994) afirma que o consumo é, numa perspetiva sociológica, a contemporânea forma de suicídio, pois se a escolha correta cria autossegurança, provavelmente uma opção errada envolve um mecanismo de autodestruição, pelo que existirão consequências para quem tome decisões transviadas. Esta obrigatoriedade de decidir poderá gerar um estado de ansiedade no indivíduo (Warde, 1994), já que cada escolha se encontra sujeita a uma pressão social (Wilska, 2002). Também Bauman (2007) afirma que os sujeitos poderão ser penalizados ao não demonstrarem possuir presteza na sua capacidade consumista. É por esse motivo que Warde (1994) afirma que o consumo pode ser uma atividade stressante. Cruz (2009) refere que, tendo em conta este cenário, o ator social socorre-se de mecanismos compensatórios e reconfortantes, como a família, os amigos e a publicidade: o que a pessoa consome não é independente do contexto em que se dão as relações estabelecidas com os outros.

Dada a intrínseca volatilidade das identidades, a habilidade consumista permite a realização de fantasias identitárias. Detendo essa capacidade, o indivíduo é livre para criar ou desfazer a sua identidade. É através da rendição ao consumo que se ganha independência (Bauman, 2000), sendo utilizado pelos atores sociais para manterem “(...) their sense of identity through time and define themselves in relationship to other people" (Ahuvia, 2005: 171). Aliás, segundo Bauman (2007), a cultura consumista carateriza-se pela constante pressão para que o indivíduo mude de identidade. No entender do autor, trata-se de um dever, disfarçado de privilégio. Para Lehtonen e Mäenpää (1997), o ato aquisitivo permite que os indivíduos modifiquem, voluntariamente, as suas identidades, equiparando-os a crianças, brincando e jogando com diversos papéis, dada a diversão implícita no processo que envolve o "eu" e os possíveis "eus".

24 Ao longo do século XX, o tempo disponível para as atividades recreativas, como o consumo, aumentou (Crane, 2000). O quotidiano é particularmente marcado pelo lazer e ócio (Campos, 2010). Ora, as atividades hedónicas centram-se na compra de bens (Miles, 2000): a mercadoria culturaliza-se, porque surge transformada em substância lúdica (Baudrillard, 1995). Apesar de a importância do consumo ser transversal à sociedade, a particular preponderância atribuída às compras varia mediante a idade, sendo mais relevante para os jovens (Miles, 2000), o género, em que as mulheres lhe atribuem especial destaque, e a urbanidade, em que um dos grandes prazeres da citadina vida moderna é dedicada a uma ética consumista (Corrigan, 1997).

$\mathrm{O}$ ato de comprar é uma atividade quotidiana social, encarada como um investimento nas relações sociais (Miller et al., 1998), uma vez que: “(...) shopping is as often about others 
as it is about self (and even when it is about self, it is often still about others)" (Miller et al., 1998: 17). O padrão de consumo constitui um poderoso meio informativo para conhecer a identidade dos indivíduos, surgindo como o fator primordial na modelação da presente sociedade, ao ser determinante no modo como os sujeitos se relacionam com os outros (Ransome, 2005; Santos, 2011). Prevalece um sistema sociológico de signos, em que o consumo surge como um modo novo e específico de socialização, como uma conduta ativa e coletiva, como coação e moral, compondo um sistema de valores (Baudrillard, 1995). A cultura de consumo possibilita a pertença social através da posse material (Darriba e Castro, 1998).

Segundo Duarte (2009), o colapso do anterior sistema de distinções naturalmente instituídas e a respetiva substituição por um sistema de estratificação transponível acabou por permitir a flexibilidade identitária. Assim, a procura de bens poderá surgir como uma forma de os indivíduos se redefinirem pessoal e socialmente, dadas as inúmeras possibilidades potenciadas por uma estrutura social variável. Uma vez que, numa hierarquia social rígida, o processo de ligação entre objetos e posições sociais permaneceria linear e relativamente controlado, com a modernidade a procura de produtos torna-se um importante mecanismo de competição social e redefinição pessoal, uma vez que os objetos são canais de expressão e reconstrução identitária.

De acordo com a autora (Duarte, 2009), para se compreender o atual papel do consumo é necessário incluir um outro conceito: a identidade. A pesquisa que efetuou, junto de vinte e quatro famílias, permitiu concluir que os pertences podem ser complementos da identidade do indivíduo e que o consumo oferece alternativas identitárias. Também a investigação operacionalizada por Cruz $(2009,2010)$, na qual se analisaram as listas de despesas (mapas mensais onde eram registados os montantes dispendidos) de trinta famílias, permitiu inferir a relação existente entre as práticas de consumo e os diferentes papéis sociais assumidos pelo sujeito. Constatou-se ainda que o consumo é a expressão de um desejo relativamente constrangido pelos deveres sociais (regras de prescrição), pelos saberes adquiridos (socializações) e pelos poderes (económicos, culturais, relacionais, entre outros).

O consumo é um ato expressivo (Tomlinson, 1990), pois os objetos são signos, em que a circulação, compra, venda e apropriação de bens constitui uma linguagem (Baudrillard, 1995). A presente sociedade, encarada como a civilização da conotação, carateriza-se pela atribuição de significados aos géneros (Barthes, 1985). Nenhum bem permanece imune à significação (Baudrillard, 1972). Aliás, Arendt (2001) alerta: chegará o momento em que nenhum pertence estará a salvo do consumo. Como os objetos possuem caraterísticas sígnicas (Santos, 2011), através da fruição dos produtos o indivíduo expressa as suas caraterísticas, ou seja, os bens tornaram-se símbolos identitários, ao tornarem visível a identidade do respetivo usuário. Nesse sentido, são efetuadas inferências acerca da pessoa com base nos artigos adquiridos, dado o caráter simbólico detido pelos bens materiais. A identidade do indivíduo é estabelecida, comunicada, confirmada, mantida, reproduzida e transformada através das relações estabelecidas com os produtos (Dittmar, 1992). Logo, o consumo é um componente identitário, articulado através das relações firmadas com os bens (Miller et al., 1998).

Ransome (2005) defende que os indivíduos empreendem dois tipos de consumo: uma satisfação quotidiana básica de necessidades e desejos e uma satisfação simbólica. É esta última esfera, associada aos estilos consumistas pós-modernos, que os sujeitos mais ambicionam atingir, encontrando-se relacionada com o "consumo de significados". 
Trata-se de uma dimensão representativa (Santos, 2011), pois o bem detém uma função social (Jhally, 1995). Ora, a significação de um símbolo não é absoluta (Appadurai, 1986), nem intrínseca, mas socialmente estabelecida (Dittmar, 1992). As mercadorias detêm potencial societal (Appadurai, 1986), pelo que os indivíduos as utilizam para se demarcarem socialmente (Jhally, 1995).

30 A ideia de que os objetos devem ser importantes para as pessoas em função daquilo para que são usados e não devido ao seu significado intangível tornou-se obsoleta (Santos, 2011): poucas são as escolhas do consumidor inteiramente racionais e instrumentais (Gay et al., 1997). A seleção de bens engloba a respetiva constante avaliação, mediante o seu potencial contributo para a projeção das identidades. Consequentemente, as opções efetuadas não são inócuas (Crane, 2000). Aliás, segundo Cruz (2010), analisar o consumo enquanto objeto de estudo pressupõe a consciencialização de que as práticas de consumo, embora complexas e difusas, não são aleatórias.

31 Para Campbell (2004), se o sujeito se confrontar com uma crise identitária, esta poderá ser resolvida com recurso ao consumo, uma vez que a atividade consumista permite que o indivíduo descubra o seu "eu". Por esse motivo, quando o sujeito se define, fá-lo, praticamente, com base nos seus gostos e preferências, por julgar serem os parâmetros que melhor o definem. Apesar de reconhecer que a resposta à pergunta "Quem sou eu?" terá de incluir critérios como: género; raça; nacionalidade; etnia ou religião, o autor relativiza a importância destas dimensões. Ora, esta conceptualização é recente. Anteriormente, a identidade encontrava-se ancorada no estatuto e posição que a pessoa ocupava nas várias instituições, tal como o trabalho e a família.

Os comportamentos de consumo, que assumem particular relevância nas sociedades contemporâneas, são, simultaneamente, práticas sociais, culturais e identitárias: é pelo consumo que o sujeito define a sua própria identidade (Cruz, 2009, 2010). Contudo, Sayre e Horne (1996) detetaram uma exceção: as vítimas de desastres naturais. 0 estudo efetuado junto de vítimas de incêndio demonstrou que, após o acidente, os sujeitos passaram a atribuir uma menor importância à posse material. A sólida relação que existia, antes do incidente, entre o "ser" e o "ter" transformou-se numa ligação de valor finito, com menor relevância na construção identitária.

33 Assim, o lugar do consumo é a vida quotidiana, o qual surge como uma instituição, ideologia (Baudrillard, 1995) ou mesmo como a religião do século XX (Miles, 2000). Apesar de o trabalho permanecer importante, é o consumo que assume um papel dominante na definição identitária (Ransome, 2005). É a atividade do consumidor, e não do produtor, que se presume providenciar a interface essencial entre os indivíduos e a sociedade (Bauman, 2007), uma vez que a vida dos atores sociais é determinada mais pela forma como consomem bens do que pela maneira como os produzem. Ora, a prática moderna da identidade liberada não poderia ter emergido até a sociedade ter atingido o estádio de consumo afluente, dada a facilidade com que promove a autónoma expressão identitária. Segundo esta lógica, qualquer insinuação de que o consumo apresenta limites equivale a sugerir que existem limitações para a quantidade de identidades que um indivíduo pode, sensatamente, esperar ter (Ransome, 2005).

Em suma, apesar de o consumo ocupar um lugar nevrálgico na construção identitária contemporânea, denota-se a ausência de um escrutínio científico sobre esta problemática no panorama sociológico internacional (Ahuvia, 2005) e nacional: a investigação na área do consumo tem sido pouco desenvolvida em Portugal (Cruz, 
2009). Falk e Campbell (1997) alertam para o facto de o consumo, quando analisado de forma superficial, poder não aparentar ser um fenómeno de particular relevância societal, dada a significância social marginal que lhe é atribuída. Urge, pois, investigar um tema com reflexos práticos no quotidiano identitário do indivíduo, uma vez que só assim será possível emitir um discurso contemporâneo sobre as novas questões que se colocam ao ator social, atualmente imerso numa sociedade de consumo.

\section{BIBLIOGRAFIA}

AHUVIA, A. C. (2005), “Beyond the extended self: loved objects and consumers' identity narratives", Journal of Consumer Research, 32, pp. 171-184.

APPADURAI, A. (1986), "Introduction: commodities and the politics of value" in A. Appadurai (ed.), The social life of things: commodities in cultural perspective, Cambridge, Cambridge University Press, pp. 3-63.

ARENDT, H. (2001), A condição humana, Lisboa, Relógio d’Água.

BARTHES, R. (1985), A aventura semiológica, Lisboa, Edições 70.

BAUDRILLARD, J. (1972), Para uma crítica da economia política do signo, Lisboa, Edições 70.

BAUDRILLARD, J. (1995), A sociedade de consumo, Lisboa, Edições 70.

BAUMAN, Z. (1995), Life in fragments: essays in postmodern morality, Oxford, Blackwell.

BAUMAN, Z. (2000), Liquid modernity, Cambridge, Polity Press.

BAUMAN, Z. (2007), Consuming life, Cambridge, Polity Press.

BOCOCK, R. (1993), Consumption, Londres, Routledge.

CAMPBELL, C. (2004), "I shop therefore I know that I am: the metaphysical basis of modern consumerism" in K. M. Ekström e H. Brembeck (eds.), Elusive consumption, Nova Iorque, Berg, pp. 27-44.

CAMPOS, R. (2010), "Juventude e visualidade no mundo contemporâneo: uma reflexão em torno da imagem nas culturas juvenis”, Sociologia, Problemas e Práticas, 63, pp. 113-137.

CORRIGAN, P. (1997), The sociology of consumption: an introduction, Londres, Sage.

COSTA, A. F. da (1992), Sociologia, Lisboa, Difusão Cultural.

COSTA, A. F. da (2008), Sociedade de bairro: dinâmicas sociais da identidade cultural, Lisboa, Celta.

CRANE, D. (2000), Fashion and its social agendas: class, gender and identity in clothing, Chicago, The University of Chicago Press.

CRUZ, I. (2010), "Entre constrangimento e criatividade: práticas de consumo em Portugal Continental”, Sociologia: Revista do Departamento de Sociologia da FLUP, XX, p.167-190.

CRUZ, I. (2009), Entre estruturas e agentes: padrões e práticas de consumo em Portugal Continental, Tese de Doutoramento, Porto, Faculdade de Letras da Universidade do Porto. 
DARRIBA, V. e L. R. de Castro (1998), “Construções identitárias e a busca da felicidade na cultura do consumo" in L. Rabello de Castro (org.), Infância e adolescência na cultura do consumo, Rio de Janeiro: Nau, pp. 90-106, in http://www.psicologia.ufrj.br/nipiac/images/stories/livros/ infancia_e_adolescencia_na_cultura_do_consumo.pdf.

DITTMAR, H. (1992), The social psychology of material possessions: to have is to be, Hertfordshire, Harvester Wheatsheaf.

DOHERTY, M. (2009), "When the working day is trough: the end of work as identity?", Work, Employment \& Society, 23 (1), pp. 84-101, in http://wes.sagepub.com/cgi/content/abstract/ $23 / 1 / 84$.

DUARTE, A. (2009), Experiências de consumo: estudos de caso no interior da classe média, Porto, Universidade do Porto.

ELIAS, N. (1993), A sociedade dos indivíduos, Lisboa, Publicações Dom Quixote.

FALK, P. e C. Campbell (1997), "Introduction” in P. Falk e C. Campbell (eds.), The shopping experience, Londres, Sage, pp. 1-14.

FEATHERSTONE, M. (1994), Consumer culture and postmodernism, Londres, Sage.

FERREIRA, P. M. (2000), “Controlo e identidade: a não conformidade durante a adolescência”, Sociologia, Problemas e Práticas, 33, pp. 55-85.

FRANKLIN, J. (1998), “Introduction” in J. Franklin (ed.), The politics of risk society, Cambridge, Polity Press, pp. 1-8.

FRIEDMAN, J. (1999), Consumption and identity, Amsterdão, Harwood Academic Publishers.

GAY, P. du et al. (1997), Doing cultural studies: the story of the Sony walkman, Londres, Sage.

GIDDENS, A. (1989), A constituição da sociedade, São Paulo, Martins Fontes.

GIDDENS, A. (2004), Sociologia, Lisboa, Fundação Calouste Gulbenkian.

GOFFMAN, E. (1982), Estigma: notas sobre a manipulação da identidade deteriorada, Rio de Janeiro, Zahar Editores.

GOFFMAN, E. (1983), “The interaction order”, American Sociological Review, 48 (1), pp. 1-17.

GONÇALVES, H. S. (1994), "Processos de (re)construção de identidades culturais num bairro de habitação social”, Sociologia, Problemas e Práticas, 16, pp. 135-149.

GOVE, J. e S. Watt (2004), “Identity and gender” in K. Woodward (ed.), Questioning identity: gender, class, ethnicity, Londres, Routledge, pp. 43-772.

HALL, S. (2005), “Quem precisa da identidade?" in T. T. da Silva (org.), Identidade e diferença: a perspectiva dos estudos culturais, Petrópolis, Editora Vozes, pp.103-133.

JHALLY, S. (1995), Os códigos da publicidade: o feiticismo e a economia política do significado na sociedade de consumo, Porto, Edições Asa.

KOPYTOFF, I. (1986), “The cultural biography of things: commoditization as process" in A.

Appadurai (ed.), The social life of things: commodities in cultural perspective, Cambridge, Cambridge University Press, pp. 64-91.

LEHMANN, L. et al. (1998), "Estetização do corpo: identificação e pertencimento na contemporaneidade" in L. R. de Castro (org.), Infância e adolescência na cultura do consumo, Rio de Janeiro: Nau, pp. 107-123, in http://www.psicologia.ufrj.br/nipiac/images/stories/livros/ infancia_e_adolescencia_na_cultura_do_consumo.pdf. 
LEHTONEN, T-K. e P. Mäenpää (1997), "Shopping in the east centre mall” in P. Falk e C. Campbell (eds.), The shopping experience, Londres, Sage, pp. 136-165.

LEWIS, G. e A. Phoenix (2004), “'Race', 'ethnicity’ and identity” in K. Woodward (ed.), Questioning identity: gender, class, ethnicity, Londres, Routledge, pp. 115-150.

MAALOUF, A. (2002), As identidades assassinas, Miraflores, Difel.

MACKINTOSH, M. e G. Mooney (2004), "Identity, inequality and social class” in K. Woodward (ed.), Questioning identity: gender, class, ethnicity, Londres, Routledge, pp. 79-114.

MEAD, G. (1967), Mind, self, \& society: from the standpoint of a social behaviourist in C. W. Morris (ed.), Chicago, The University of Chicago Press.

MILES, S. (2000) Youth lifestyles in a changing world, Buckingham, Open University Press.

MILLER, D. et al. (1998), Shopping, place and identity, Londres, Routledge.

NUNES, A. S. (1968), Sociologia e ideologia do desenvolvimento, Lisboa, Moraes Editores.

OTTO, H. A. e S. T. Otto (1971), “A new perspective of the adolescent” in Hershel D. Thornburg (ed.), Contemporary adolescence: readings, Belmont, Wadsworth Publishing, pp. 404-410.

PAIS, J. M. (2002), Sociologia da vida quotidiana, Lisboa, Imprensa de Ciências Sociais.

PINTO, J. M. (1991), “Considerações sobre a produção social de identidade”, Revista Crítica de Ciências Sociais, 32, pp. 217-231.

QUADRADO, R. (2006), Adolescentes: corpos inscritos pelo gênero e pela cultura de consumo, Tese de Mestrado, Rio Grande, Fundação Universidade Federal do Rio Grande, in http://www.bibliotecaacaoeducativa.org.br/dspace/bitstream/123456789/1841/1/tese.pdf.

QUEIROZ, M. C. (2005), Classes, identidades e transformações sociais: para ler as evoluções da estrutura social portuguesa, Porto, Campo das Letras.

RANSOME, P. (2005), Work, consumption and culture: affluence and social change in the twentyfirst century, Londres, Sage.

RATTANSI, A. e A. Phoenix (2001), "Rethinking youth identities: modernist and postmodernist frameworks" in John Bynner et al. (eds.), Youth, citizenship and social change in a European context, Aldershot, Ashgate, pp. 121-150.

SANTOS, C. (2011), “A dimensão simbólica do discurso publicitário", Biblioteca on-line de Ciências da Comunicação, Covilhã, UBI, in http://www.bocc.ubi.pt/pag/santos-cristina-a-dimensao-simbolicado-discurso-publicitario.pdf.

SAYRE, S. e D. Horne (1996), "I shop, therefore I am: the role of possessions for self definition", Consumer Research, 23, in K. Corfman e J. Lynch Jr. (eds.), pp. 323-328, in http:// www.acrwebsite.org/volumes/display.asp?id=7975.

SCHWARTZ, P. (1999), “A personal passage: identity acquisition and affinity groups” in B. Glassner e R. Hertz (eds.), Qualitative sociology as everyday life, Thousand Oaks, Sage, pp. 159-167.

SILVA, T. T. da (2005), “A produção social da identidade e da diferença” in T. T. da Silva (org.), Identidade e diferença: a perspectiva dos estudos culturais, Petrópolis, Editora Vozes, pp. 73-102.

TARLO, E. (1996), Clothing matters: dress and identity in India, Londres, Hurst \& Company.

TOMLINSON, A. (1990), "Introduction: consumer culture and the aura of the commodity" in A. Tomlinson (ed.), Consumption, identity, \& style: marketing, meanings, and the packaging of pleasure, Londres, Routledge, Comedia book. 
TOURAINE, A. (1982), Pela sociologia, Lisboa, Publicações Dom Quixote.

VELHO, G. (1994), Projecto e metamorfose: antropologia das sociedades complexas, Rio de Janeiro, Jorge Zahar Editor.

VIEIRA, R. (1999), Histórias de vida e identidades: professores e interculturalidade, Porto, Edições Afrontamento.

WARDE, A. (1994), "Consumption, identity-formation and uncertainty”, Sociology, 28 (4), Sage, pp. 877-898, in http://soc.sagepub.com/cgi/content/abstract/28/4/877.

WIEVIORKA, M. (2007) “Diferenças nas diferenças?”, Trajectos: Revista de Comunicação, Cultura e Educação, 11, Lisboa, ISCTE, pp. 85-97.

WILSKA, T.-A. (2002), “Me as a consumer? Consumption, identities and lifestyles in today's Finland”, Acta Sociologica, 45, pp. 195-210, in http://asj.sagepub.com/cgi/content/abstract/ 45/3/195.

WOODWARD, K. (2004), “Questions of identity” in K. Woodward (ed.), Questioning identity: gender, class, ethnicity, Londres, Routledge, pp. 6-22.

WOODWARD, K. (2005), “Identidade e diferença: uma introdução teórica e conceitual” in T. T. da Silva (org.), Identidade e diferença: a perspectiva dos estudos culturais, Petrópolis, Editora Vozes, pp. 7-72.

YBEMA, S. et al. (2009), “Articulating identities”, Human Relations, 62 (3), Sage, pp. 299-322, in http://hum.sagepub.com/cgi/content/abstract/62/3/299.

\section{RESUMOS}

Com o presente artigo pretendemos inferir qual o lugar que o consumo ocupa na problemática identitária contemporânea. Para o efeito, efetuámos uma revisão da literatura, na qual procurámos dissecar e discutir as várias perspetivas que abordam os dois conceitos principais: identidade e consumo. Com base na reflexão teórica realizada, concluímos que a dinâmica consumista emergente tem repercussões efetivas na construção de uma identidade. De facto, através do consumo, atividade central na vida do indivíduo, geram-se práticas identitárias. Apesar de considerarmos tratar-se de uma temática atual, oportuna e pertinente, denota-se a escassez de obras que abordam a problemática no panorama sociológico português (Cruz, 2009). Assim, com esta comunicação intentar-se-á contribuir para a clarificação do tema, o qual esperamos que possa ser objeto de mais e novos aprofundamentos cognitivos, dadas as implicações e os desafios que levanta no tecido social.

The aim of the present article is to infer the role consumption takes place in the contemporary identity problematic. For this purpose, we did a review of the literature, in which we tried to dissect and discuss the various perspectives that address the two main concepts: identity and consumption. Through a theoretical reflection, we concluded that the emerging consumption dynamics has effective repercussions on the construction of identity. In fact, through consumption, central activity in the individuals' lives, identity practices are generated. Although we consider that this is a current and relevant theme, it is visible the lack of literature on the topic in the portuguese sociological overview (Cruz, 2009). Thereby, with this communication we hope to contribute to the clarification of the theme, which we hope it will have more and new cognitive insights, given the implications and the challenges it raises to the social tissue. 
ÍNDICE

Keywords: identity, consumption, contemporaneity

Palavras-chave: identidade, consumo, contemporaneidade

AUTOR

CRISTINA SANTOS

Universidade Lusófona de Humanidades e Tecnologias (cristina.afsantos@gmail.com) 